\title{
Invited review: Reproductive and genomic technologies to optimize breeding strategies for genetic progress in dairy cattle
}

\author{
Allison Fleming ${ }^{1}$, Emhimad A. Abdalla ${ }^{1}$, Christian Maltecca ${ }^{2}$, and Christine F. Baes ${ }^{1}$ \\ ${ }^{1}$ Centre for Genetic Improvement of Livestock, Department of Animal Biosciences, Guelph, Ontario, \\ N1G 2W1, Canada \\ ${ }^{2}$ Department of Animal Science, North Carolina State University, Raleigh, North Carolina 27695, USA
}

Correspondence: Christine F. Baes (cbaes@uoguelph.ca)

Received: 24 October 2017 - Revised: 6 December 2017 - Accepted: 11 December 2017 - Published: 23 January 2018

\begin{abstract}
Dairy cattle breeders have exploited technological advances that have emerged in the past in regards to reproduction and genomics. The implementation of such technologies in routine breeding programs has permitted genetic gains in traditional milk production traits as well as, more recently, in low-heritability traits like health and fertility. As demand for dairy products increases, it is important for dairy breeders to optimize the use of available technologies and to consider the many emerging technologies that are currently being investigated in various fields. Here we review a number of technologies that have helped shape dairy breeding programs in the past and present, along with those potentially forthcoming. These tools have materialized in the areas of reproduction, genotyping and sequencing, genetic modification, and epigenetics. Although many of these technologies bring encouraging opportunities for genetic improvement of dairy cattle populations, their applications and benefits need to be weighed with their impacts on economics, genetic diversity, and society.
\end{abstract}

\section{Introduction}

The demand for dairy products is expected to increase rapidly in the near future due to the growing middle classes in emerging economies and a general global population increase. To remain competitive and to meet growing demand, livestock industries will need to increase their production efficiency. This will require further increasing total production without increasing costs, while maintaining or even improving product quality. In recent years, myriad cutting-edge genomic technologies, methodologies and phenotype collection methods for novel traits have emerged. In particular, the dairy industry has been quick to implement these technologies in routine breeding programs, allowing for further gains in accuracy of breeding values, and the inclusion of novel functional traits. There is a need to systematically analyze, assess, and understand the implications of applying these novel genomic technologies, methodologies, and phenotype collection methods on a large scale.
Here we provide an overview of past and current genomic technologies, which have had or are likely to have disruptive effects on current livestock breeding practices. We include discussion on reproductive technologies, advances in genomic and epigenomic technologies, and genetic modification. Considerations for the adoption of these technologies are also discussed, including their effects on genetic diversity, economics, and social acceptance.

\section{Reproductive technologies}

Increasing output per unit input has generally been the main objective in dairy cattle breeding programs. Selective breeding for economically important traits, which has traditionally been based on phenotypic recordings and has more recently been based on genomic selection, has produced animals with high genetic merit. In order to disseminate high-merit genetics, reproductive technologies have been optimized in parallel (Flint and Woolliams, 2008). The decline of dairy cattle fertility is a worldwide phenomenon of great concern. Hence, 
reproductive technologies aimed at improving reproductive efficiency have been a high priority and will play a crucial role in meeting the rising challenges of food supply (Murphy, 2012). Over the past five decades, as milk production per cow has increased, fertility in dairy cows has declined. Although research to improve reproduction in dairy cattle has advanced, it is still a challenge for high-performing dairy cows (e.g. Pryce et al., 2004; Walsh et al., 2011).

Modern reproductive technologies have been integrated with the latest genetic selection tools to improve economically important traits, including fertility (Veerkamp and Beerda, 2007; Berendt et al., 2009). While reproductive technologies are designed to help with everyday farm-level management problems, genetic selection is aimed at increasing fertility on a long-term genetic basis. Since many factors affect fertility traits, and the phenotypes currently collected are quite removed from the actual biology of the animals (e.g. non-return rate, interval from calving to first service), the accuracy of breeding values for fertility is generally low. For instance, environmental conditions such as nutrition, stress, temperature, or presence of pathogens have a great impact on fertility traits and reduce the recording accuracy of these traits. Nevertheless, genome-wide association studies (GWASs) have been successfully applied to fertilityrelated traits and several quantitative trait loci (QTL) were detected (Veerkamp and Beerda, 2007; Sahana et al., 2010; Khatib, 2014). In addition, functional genomic approaches have been applied to some traits such as early embryo development and conceptus-maternal interactions, which are important for a successful gestation (e.g. Mondou et al., 2012; Walsh et al., 2012), as well as for embryo quality (e.g. Jaton et al., 2017).

Recently, studies based on gene expression and epigenetics were used to analyze fertility traits (Inbar-Feigenberg et al., 2013; Kohda and Ishino, 2013). The underlying idea was that biological systems can be adapted to environmental conditions, and the reproductive system, in particular, has shown that long-term consequences are a result of some stress applied early during development. The research focus is now on better understanding how early events affect later performance. Walsh et al. (2011) reported that the decline in fertility in dairy cattle can be attributed to metabolic stress as a result of negative energy balance during early lactation. Heifers born from these dairy cows would then have lower ovarian reserves and hence lower fertility. The longterm impact of the uterine environment has also been of interest, which could lead to the selection of better recipients for embryo transfer. Several studies showed that rearing conditions of heifers and young bulls play important roles and may modulate the impact of the epigenome. The following describes several aspects of current and emerging reproductive technologies that are designed to accelerate the rate of genetic improvement in dairy cattle.

\subsection{Artificial insemination}

Artificial insemination (AI) and how it has contributed to the progress in dairy cattle breeding and production programs is reviewed in this section. Given the ease of access and the ability of males to produce high rates of gametes, AI has been the main focus of reproductive technologies. This could be the greatest advantage of AI as it makes maximal use of superior bulls. The AI industry has grown tremendously since its beginning. The first successful insemination was performed in a dog more than two centuries ago (1784). In the later 100 years, it was also used for study purposes in rabbits, dogs, and horses. The first time AI was used as a practical procedure in farm animals was by Ivanow in the early 20th century (Foote, 2002). In 1968, AI usage enabled one dairy sire to provide semen for more than 60000 services, and the United States Department of Agriculture reported in 1970 that 7344420 dairy females were bred artificially (i.e. $46 \%$ of the female dairy cattle population). The export markets, especially for Holstein semen in the 1980s, led to huge improvements in the AI scheme (Foote, 2002; Funk, 2006). Foote (2002) indicated that AI is one of the biotechnologies that has been accepted worldwide and widely used to improve reproduction and genetics of farm animals. The author added that all other associated techniques, such as semen freezing, sexing, synchronization, and timing of insemination, were established after the wide success of AI. Specifically, these techniques were found to increase the efficiency of AI. For instance, oestrus synchronization is being regularly combined with $\mathrm{AI}$ in a technique known as timed AI (TAI). Quality oestrus detection is required for successful AI, which can represent a challenge for some herds. Without correct detection of oestrus, the efficiency of AI is low (Sales et al., 2011). However, when oestrus synchronization is implemented, the efficiency of $\mathrm{AI}$ is increased and oestrus detection is no longer necessary. It has been reported that several artificial reproduction techniques could be the cause of abnormal epigenetic regulation, but the findings in this regard are still limited (Kremenskoy et al., 2006). Nevertheless, the trend now in AI industries is breeding for improved fertility, longevity, and profitability in dairy cattle through an emphasis on non-production traits. In addition, linebreeding pure breeds and applying crossbreeding programs to overcome inbreeding depression have been considered (Funk, 2006).

\subsection{Sexed semen}

Sexed semen has long been a dream for dairy cattle breeders and has brought a revolution to the dairy industry. Arguably, it could be considered as the latest disruptive breakthrough in animal reproduction, and the process of commercialization has recently gained more momentum. In the dairy industry in particular, the practical implementation of this technique is well underway. Sexing semen can be used to produce offspring of the desired sex, and hence could be of value for 
improving production efficiency through producing replacement heifers from genetically superior animals (Seidel Jr., 2012; Boro et al., 2016). Despite the advantage of predetermination of sex on profitability, it is generally of little value for increasing the rate of genetic improvement. Increasing the proportion of one sex compared to other is not expected to improve genetic merit for animals, although the overall sample size of selection candidates is increased. In addition, the technology is arguably hindered by factors such as lower pregnancy rates, as well as high costs, and such drawbacks preclude widespread application at the commercial level in dairy cattle (Garrick and Ruvinsky, 2014).

\subsection{Embryo transfer}

Embryo transfer is another technique used to increase the number of offspring from genetically superior females. Since commercialization in the early 1970s, embryo transfer has been regularly used in dairy cattle breeding (Mikkola et al., 2015; Mikkola and Taponen, 2017). Despite the fact that this technique has been used commercially for about 50 years, the improvement in this field has been relatively slow and the number of transferable embryo from a single donor in a single embryo collection remained at the same levels (Mikkola and Taponen, 2017). Several factors, including those animalrelated and those involving environment and management, contribute to the lower outcomes of embryo transfer. Heat stress and the inefficiency of oestrus detection in dairy herds represent the main management challenges. Oestrus detection is a serious problem since high-producing cows display shortened oestrus periods and less obvious behavioral symptoms of oestrus (e.g. Macmillan, 2010; Walsh et al., 2011). An alternative technique has been proposed to make embryo transfer independent of oestrus detection, namely fixed-time embryo transfer (FTET) (Rodrigues et al., 2010). One of the advantages of this procedure is that it results in higher pregnancy rates through increasing the number of well-synchronized recipient cattle (Baruselli et al., 2011; Rodrigues et al., 2010). The FTET is similar to TAI described above where both techniques allow timed breeding without the need for oestrus detection. The current trend of research in this area is to improve this protocol and increase its efficiency (Baruselli et al., 2011; Bó et al., 2011).

\subsection{Synchronization}

Over the lactation period, dairy cattle go through different follicular wave dynamics due to ovarian follicular growth and development. This phenomenon, which becomes more dramatic as milk production increases, has a large effect on the reproductive physiology of cows. Currently, synchronization is being used to overcome reproductive inefficiencies in dairy cows (Wiltbank et al., 2011). Synchronization of oestrus and/or ovulation has also been applied on dairy cows to reduce the interval between calving and conception (Macmil- lan, 2010). Several synchronizing protocols have been developed and modified for dairy cattle, with some more effective than others. Even though synchronizing oestrus synchronizes the time of ovulation as well, Rabiee et al. (2005) showed that this process may not be sufficient to obtain good success rates with TAI. On the other hand, high-producing cows, in particular, may display a shortened oestrus period and less obvious behavioral symptoms of oestrus when oestrus synchronization is performed (e.g. Macmillan, 2010; Walsh et al., 2011; Wiltbank et al., 2011). Due to this problem, the trend now is to use ovulation synchronization to avoid the need for oestrus detection in timed breeding protocols. Ovulation synchronization can be considered the main component of modern forms of AI and embryo transfer (ET) protocols such as fixed-time artificial insemination (FTAI) or fixed-time embryo transfer (FTET) (Mapletoft and Bó, 2011; Walsh et al., 2011).

The incorporation of genetic improvement into the application of reproductive technologies is increasing. In the past, the main focus was to improve AI and semen cryopreservation. Although the maternal contribution has been the main objective of reproductive technology studies, more attention is being given to the sire (Kropp et al., 2017). Recently, Khatib (2014) defined a group of single nucleotide polymorphisms (SNPs) associated with bull fertility. The overall goal is to improve all of the elements that lead to reducing days open and increase the number of descendants per cow. Breeding companies are currently looking into increasing the merit of next-generation animals through integrating the latest genomic selection tools with the most advanced reproductive technologies. Genomic selection is a powerful tool that potentially facilitates prediction the genetic merit for young bulls readily at birth or even earlier through embryonic biopsy. This could efficiently lead to offspring from prepubertal parents, especially if it was combined with improving the functions of the gonads and maximizing in vitro embryo production. Moreover, the conditions pre- and postconception, as well as gestation, and pre- and post-puberty should be carefully considered since they have a great impact on the fertility of animals in the long term and in the next generation. The effect of these factors during the life of the animal has initiated a new field of study and research that is expected to contribute highly in improving cattle fertility.

\subsection{Cloning}

Producing one or more copies of an individual through embryo splitting or nuclear transfer is called artificial cloning. It can occur naturally, but at low levels (Hansen, 2014). It is an extreme form of reproductive boosting and has been long utilized in plant breeding. Cloning allows for a group of genes that work well for an individual to be replicated with the same combination pattern in another individual. Normal breeding cycles may break down this type of favourable partnership between a set of genes that an individual carries. 
For this reason, one may think of cloning as a way to reproduce superior animals. On the other hand, it does not change the genetic variation which is required to choose new elite, high-performing individuals in the future. One of the main advantages of cloning is to generate genetically identical copies of the next top bulls (Moore and Thatcher, 2006). The most popular technique used in cloning dairy cattle is cleavage-stage blastomere separation, which is used to produce multiple monozygotic calves (twins, triplets, or quadruplets). The other procedure is embryo bisection technique on post-compacted embryos, which is used to produce mainly identical twins (Rho et al., 1998; Tagawa et al., 2008). Both techniques have shown higher levels of efficiency to yield monozygotic twins after laparoscopic transfer to recipient cows. In addition, they have proven satisfactory pregnancy rates. In addition, the efficiency of cow embryo splitting was $60 \%$ or higher (Garrick and Ruvinsky, 2014). RodriguezMartinez (2012) showed that cloning could be also used for somatic cells to generate transgenic animals by cloning genetic copies of genetically superior animals.

\section{3 "Omics" technologies}

The "omics" technologies refer to a collective of study fields across all facets of biology that look at various biological molecules and their influence on the structure, function, and dynamics, or phenotype of an organism (Coughlin, 2014). The related suffix -ome is used to address the objects of study in these fields, such as the genome, epigenome, proteome, and metabolome (Coughlin, 2014), whereby only genome and epigenome are discussed in this review. Over the past few years, there has been remarkable development in these fields. The grand challenge, however, is to integrate various forms of "omics" data together to provide insight into the complex biological systems within living organisms (Suravajhala et al., 2016). Most biological traits are controlled by a large number of genes, which, in addition to their additive effects, may interact with each other, and their expression might be altered based on a variety of environmental effects. For instance, identifying a group of genes based on GWAS provides evidence that a causal relationship between a phenotype and a SNP may exist. These findings of GWAS, however, do not improve our understanding of complex traits in which many pathways may be involved (van der Sijde et al., 2014; Abdalla et al., 2016). In such case, additional "omics" information could provide a more fine-grained understanding of the association pattern, which is beyond the scope of the genome alone (Toyoda and Wada, 2004; Wang et al., 2007; Chasman, 2008).

The fast development in "omics" technologies provides opportunities to investigate the genome and epigenome, as well as the possibility of their further implementation in animal breeding methods. A number of potential and current applications of these technologies are discussed in the following sections.

\subsection{Genotyping technologies}

Early breeding decisions in dairy cattle production were based on phenotypic observations and the artful skill of breeders. With time, dairy cattle breeding evolved into a science with better understanding and appreciation of the inheritance of several important traits. Pedigree information and dairy production recording programs provided the initial datasets for estimation of genetic merit and improvement of dairy breeds. Major developments also occurred with the introduction of selection index theory (Hazel, 1943) and best linear unbiased prediction (BLUP) methodologies (Henderson, 1953, 1975). Substantial genetic gains were made using these breeding strategies in many areas, including highheritability milk production traits. Although the combination of extensive pedigree data and phenotypes enhanced selection programs, breeding for low-heritability traits, such as fertility and health, and other hard-to-phenotype traits, compelled the exploration of novel methods to achieve increased accuracies.

\subsubsection{Marker-assisted/genomic selection}

The emergence of genomics was initially slow, but has exploded in the last decade. Pioneering researchers in the application of molecular genetics in livestock began by using DNA markers to identify genes or regions of the genome controlling traits of interest. Various types of molecular markers were used to characterize genetic polymorphisms in dairy cattle and aid in the movement towards application of marker-assisted selection (MAS). Restricted fragment length polymorphisms (RFLPs), a type of early hybridization-based marker, were often used. These markers exhibit Mendelian inheritance and most are co-dominant (both alleles can be detected in a heterozygote). The development of polymerase chain reaction processes (Mullis et al., 1986) delivered opportunities for new genetic markers, including microsatellites or single sequence repeats. Microsatellites are informative, multi-allelic, codominant markers, which provided a more efficient method for characterizing genetic variation. More recent sequencing technologies have allowed the discovery of SNP, found where different nucleotide bases appear at a given position in a DNA sequence. Advantages of SNP markers are their prevalence and thus a stronger likelihood to be near or in a locus of interest; they may be located in coding regions where they could be directly responsible for some of the variation observed, they are stably inherited, and are suitable for high-throughput genetic analysis (Beuzen et al., 2000).

The genomic markers discovered around the bovine genome firstly found applications for parentage verification, genetic defect testing (e.g. leukocyte adhesion disorder; 
Shuster et al., 1992), and identification of markers that explain variation of a phenotype. Traits to benefit from MAS include those routinely recorded, difficult to record traits, and unrecorded traits (Dekkers, 2004). Numerous association studies identifying QTL, a genomic region affecting a quantitative trait, were performed, the results of which could be used to select animals by MAS. Markers may be direct causative variants or be in linkage disequilibrium or linkage equilibrium with a QTL (Dekkers, 2004). Markerassisted selection allowed animals to be selected based on their genotypes alongside available phenotypic records. This allows for earlier selection of candidates, thus lowering the generation interval and reducing costs of progeny testing, and can also help differentiate the genetic merit of relatives by capturing the random Mendelian sampling term. The genetic gains achieved using genetic markers and uptake of the methods were lower than anticipated due to the low number of markers available, the high cost of genotyping, demanding calculations of breeding values, the relatively low proportion of variation explained by genetic markers for many quantitative traits, and low association (or linkage disequilibrium) between markers and QTL (Dekkers, 2004; Hayes et al., 2009; Boichard et al., 2016).

In 2001, Meuwissen et al. (2001) showed that, using a proposed method of genomic selection, it was possible to predict breeding values with high accuracy from dense marker panels alone. With this method, information from SNP, even with small effects, could be combined and exploited. Dense marker panels were required to optimally perform MAS to ensure markers were close to the QTL, and the genome was sufficiently covered. The discovery of many more SNPs was made possible by advances in technology and molecular genetics, and SNP array panels were marketed for genotyping selection candidates. The release of the influential Illumina Bovine SNP50 chip in 2008 permitted efficient genotyping of over 54000 SNP simultaneously, which were highly polymorphic in different breeds and evenly spaced across the genome (Matukumalli et al., 2009). This greatly improved the uptake and utility of genomic selection. A further development was the addition of a low-density SNP chip enabling the accurate imputation of genotypes up to those of higherdensity panels (Boichard et al., 2012), reducing the costs of genotyping, thereby aiding in the generation of a larger reference population for the estimation of genomic breeding values and greater adoption of genotyping technologies. Various SNP panels have now been made available, including high-density panels giving more dense coverage. The implementation of genomic selection strategies in dairy breeding has successfully accelerated the rate of genetic gain in many traits of interest in dairy cattle and changed the landscape of selection. However, accuracies achieved in genomic selection still may be improved. Only variants that have been discovered and incorporated into maps can be included in genomic selection, and QTL appearing in low frequencies may not be captured.

\subsubsection{Next-generation sequencing}

The growing use of genotyping technologies has generated a large quantity of genomic information on the dairy population. Since the draft sequence of the bovine genome was published in 2009 (Zimin et al., 2009), whole-genome sequence data of cattle have also become available.

Fuelled by decreasing costs, advances in next-generation sequencing (NGS) technologies enable identification of more complex forms of genetic variation (e.g. short insertions and deletions (INDELs), copy number variations (CNVs), precise genome-wide linkage disequilibrium patterns; Wang et al., 2017) than previously possible. These advances foster our ability to partition the genetic variance underlying traits of interest. While some applications of NGS require de novo sequencing of an individual organism, re-sequencing may also be possible if a reference genome for the species of interest is available, and the collection of publicly available reference genome sequences is growing rapidly. Moving from array data (3k-777k SNPs) to sequence data, researchers hope to attain higher accuracy of breeding values, be able to gain knowledge on across-breed evaluations, and obtain a better biological understanding of the genome, as causal variants are expected to be included in the datasets through increased density of information.

Alongside rapid technological advancement and improved computing power, sequencing has underlined the need for researchers to collaborate. In the case of cattle, the 1000 bull genomes project (Daetwyler et al., 2014) provides participating members of the bovine research community access to a large database of genetic variants for imputation, genomic prediction, and GWAS in all cattle breeds, now including both Bos taurus and Bos indicus. These efforts have resulted in many international partner contributions, making the creation of a reference population much quicker than if each partner had re-sequenced on their own. There are a minimum set of standards (e.g. read depth, phred scores) for participation, and variant identification is done on a rolling basis; there are currently over 2000 animals included.

The most commonly used cattle reference genome UMD3.1 is similar in size to the human genome and contains $\sim 2.8$ billion base pairs, approximately $10 \%$ of which are not assigned to any chromosome (Zimin et al., 2009). The Btau reference genome was also published in 2009 (Elsik et al., 2009) but is less frequently used. The translation of raw NGS reads into tangible variants (SNVs, INDELs, $\mathrm{CNVs}$, etc.) via re-sequencing is a specific, delicate, and computationally demanding task (Horner et al., 2010) and comprises three steps: alignment, variant identification, and quality checks. Despite its usefulness, variants identified using the current bovine reference genome are not necessarily accurate in terms of alignment, variant identification, and further downstream analysis (Baes et al., 2014). Despite this, algorithms and software for application in GWAS and genomic 
selection programs are available, and a number of studies have been published using whole-genome sequence data.

In contrast to the read-depth required for variant discovery in individual animals, low-coverage genotyping methods such as genotyping by sequencing (GBS) are also emerging (Elshire et al., 2011). Using this approach, the cost of sequencing per animal can be lowered to below USD 10 per sample (Poland et al., 2012), which is low-cost compared to SNP chip technology, which currently has costs ranging from USD 35 to 150 depending on the necessary density. However, the proportion of correctly identified SNPs is much lower than genotypes acquired from a SNP panel (Sampson et al., 2011). Although relationships between individuals can be estimated well from GBS data (De Donato et al., 2013), the quality of variants identified across an individuals' genome is inconsistent, significantly complicating implementation of GBS data in genomic evaluation programs. This is especially problematic for heterozygous genotypes, which are more difficult to identify correctly at lower depth of sequence coverage (Baes et al., 2014). If methods to ensure the quality of sequence calls at low coverage can be developed, Gorjanc et al. (2015) showed by simulation that acceptable accuracy could be achieved. Methods to determine the true quality of low read-depth calls and detect heterozygous sites will be needed for effective GBS to take place, especially if the future of genomic selection of livestock includes the estimation of dominance components (Aliloo et al., 2016).

\subsection{Methylation and gene expression analyses}

Adding a methyl group to carbon 5 of the cytosine ring, which is referred to as DNA methylation, leads to modification of the DNA in most organisms. DNA methylation is one of the main epigenetic phenomena and has a large effect on gene expression. The dynamic changes in the epigenome play a key role in a variety of biological processes, particularly in health and production traits (Mills and Ramsahoye, 2002). Epigenetic mechanisms, such as DNA methylation, histone modification, and microRNA, influence gene expression and phenotype, but without a change in DNA sequence. The epigenetic status of an individual can be influenced by environmental stimuli experienced both in utero and ex utero, and these influences could be transgenerational (e.g. Grossniklaus et al., 2013; Heard and Martienssen, 2014; Blake and Watson, 2016). Despite the limited number of epigenetic studies in dairy cattle, they have covered milk production (Singh et al., 2010), reproduction (Sun et al., 2013; Walker et al., 2013; Saadi et al., 2017; O'Doherty et al., 2014), ageing (Green et al., 2015), and health (e.g. Green and Kerr, 2014; Doherty et al., 2016). As shown in a review by Couldrey and Cave (2014), it is now possible to analyze the available profiles and genome-wide methylation patterns that match at the single-nucleotide resolution. Understanding epigenetics in dairy cattle may potentially lead to the discovery of new breeding tools, treatments, and management practices in dairy farms. Here, we discuss several gene expression and methylation studies and roles that DNA methylation plays in controlling gene expression with more focus on dairy cattle.

A considerable proportion of unexplained phenotypic variation in dairy cattle milk production could be attributed to epigenetic regulation (Singh et al., 2010). Diverse environmental factors and management practices such as nutrition, milk frequency, photoperiod, udder health, and hormonal and local effectors may influence the number of mammary epithelial cells, which affects milk production in dairy cattle. In addition, the effects of maternal milk production negatively influence daughter milk yield. Arguably, highproducing cows tend to be in greater negative energy balance and hence greater metabolic stress during pregnancy, with subsequent negative effects on the lactation performance of daughters.

During pregnancy, it has been hypothesized that DNA methylation influences the expression of key genes in the uterus. Based on samples from the endometrium of fertile and subfertile dairy cow strains, DNA methylation and gene expression were correlated in several pathways implicated in early pregnancy events (Walker et al., 2013). Genes involved in these pathways showed negative correlations, which indicate that the effect of the DNA methylation contributes to changes in expression of endometrial genes. In fertile and subfertile strains, correlations between DNA methylation and gene expression were also observed for genes that were differentially expressed. These findings suggested that DNA methylation could significantly contribute to the difference in fertility between these two strains of dairy cows. While the results of this study prove the correlation between DNA methylation and gene expression, they do not show the causation between them. Recently, Saadi et al. (2017) reported that dairy bulls that are monozygotic twins may not carry identical genetic merit estimates and may show different breeding values. Despite their identical genetic backgrounds, paternal sperm epigenomes may vary between monozygotic twin bulls, which may explain the variation in the productivity of their offspring. The experimental evidence for this hypothesis was obtained by characterizing DNA methylation for the monozygotic twin bulls. Among the 400000 probes used, 2 to $10 \%$ were differentially methylated between each pair of the monozygotic twins. Moreover, across all pairs of monozygotic twins, 580 loci were differentially methylated. Further investigations are required to define the causative relationship between DNA methylation and gene expression during pregnancy. The candidate genes that are involved in this mechanism have been highlighted and defined. In addition, differences in the sperm epigenome should be considered for further research and daughters of monozygotic twin bulls may diverge in performance. Several studies in the literature have reported the effect of epigenetic and gene expression on health traits in dairy cattle (Doherty et al., 2016; Green and Kerr, 2014; Paibomesai et al., 2013). Most of the DNA methylation studies on health traits focused on the im- 
mune system and dairy cattle which may respond differently based on the regulations of DNA methylation. In 2013, Paibomesai et al. (2013) reported that the epigenetic mechanism, DNA methylation, may affect the adaptive immune system cells in dairy cattle. This effect was most obvious during the peripartum period. The variation in immune system response during this period was in parallel with the DNA methylation of IFN- $\gamma$ and IL- 4 promoter regions. These two regions could be epigenetically controlled since the DNA methylation increased during the partum period. A year later, another study investigated the relation of gene expression to the response of the innate immunity, which plays a key role in recognition and early response to pathogens (Green and Kerr, 2014). The authors reported that epigenetics had significantly regulated the innate immunity response. Doherty et al. (2016) studied bovine tuberculosis to find out how epigenetics shifts CD4+ T lymphocytes into dysfunctional $\mathrm{T}$ cells and influences their ability to clear mycobacterial infection. They found that DNA methylation had a direct effect on CD4+ T cells in the infected cattle. During mycobacterial infection, methylation of specific loci lead to the development of the non-protective CD4+ T cell.

\section{Genetic modification}

The knowledge emerging from identification of variants within the genome has led to the concept of human intervention at the genome level by alteration of the host genome through the introduction of genes or other modifications to produce desirable results in ways never before possible in dairy cattle. Genetic modification has a great potential for various applications within the dairy industry to benefit producers, consumers, and society.

\subsection{Genetic engineering}

Genetic engineering can be defined as a process by which desirable traits are introduced into an organism using recombinant DNA (rDNA) technology (Van Eenennaam, 2017). This technology provides breeders with access to genetic variation that would normally be unobtainable in the species of interest. The first genetically engineered animals appeared in the 1980s with mice (Brinster et al., 1981), followed shortly thereafter by livestock species (Hammer et al., 1985). The initial tool applied for genomic engineering of livestock was pronuclear injection, which involved the injection of DNA into pronuclei of fertilized eggs (Hammer et al., 1985). This method was leading in the early research of genetically engineered livestock but was hampered by low efficiency and the random integration of DNA into the target genome. Some improvements were achieved following the arrival of viral transformation methods (Chan et al., 1998). A major advancement in advanced reproductive technologies with somatic cell nuclear transfer (SCNT) cloning and the birth of Dolly the sheep (Wilmut et al., 1997) also provided aid in the generation of genetically engineered livestock. SCNT allows for the production of transgenic offspring from selected and screened transgenic cells within a line to ensure cells express the transgene before they are transferred into the oocyte. However, with SCNT there remains the matter of gestational losses, abnormalities, and low numbers of resulting live offspring (Keefer, 2015).

Applications in livestock that have been investigated involve improving production yields and quality, animal health, and welfare. The livestock models for genome editing focused chiefly on highly fecund species like pigs and other small species like sheep and goats. Large bovine species have added difficulties due to poor efficiencies and long gestation periods. In dairy cattle, targets have primarily revolved around alteration of milk to improve its composition for human consumption and for improved udder health of the lactating cow. Using microinjection, van Berkel et al. (2002) produced transgenic cattle lines expressing recombinant human lactoferrin in milk, illustrating the production of biopharmaceuticals by dairy cows. Other work has also looked to alter the protein in bovine milk using genetically engineered cattle, including increasing beta- and alpha-caseins (Brophy et al., 2003), the incorporation of human lysozyme (Yang et al., 2011), and the decrease in beta-lactoglobulin (Jabed et al., 2012). A relevant application of genomic engineering in dairy cattle is also for the promotion of optimal cow health and disease resistance to improve welfare and the viability of the population. Wall et al. (2005) reported transgenic Jersey cows secreting lysostaphin were protected against Staphylococcus aureus mastitis. Listings of the various other works undertaken in the genetic engineering of livestock species can be found in reviews by Laible et al. (2015) and Lievens et al. (2015).

The acceptance of genetically engineered animals has been slow due to a variety of concerns including food safety, environmental impact, welfare, ethical concerns, unknown consequences of intended changes to the genome, and general perceptions and willingness of the public. The production of human drugs from genetically engineered livestock has been more received than food products from genetically engineered animals. European regulators first approved genetically engineered animals as bioreactors for biomedical pharmaceutical production including $\operatorname{ATryn}{ }^{\circledR}$ (human antithrombin-III) produced in goat milk. To date, the AquAdvantage Salmon ${ }^{\circledR}$ is the lone genetically engineered animal approved for entry into the food supply and has been sold unlabelled in the USA and Canada since 2016. The AquAdvantage Salmon ${ }^{\circledR}$ grows to market size faster than non-genetically engineered Atlantic salmon thanks to the addition of an rDNA construct composed of the growth hormone gene from Chinook salmon under the control of a promoter from ocean pout (Cook et al., 2000). The salmon was first generated in 1989 and underwent an exhaustive approval process to prove its safety and environmental impact. The Enviropig $^{\circledR}$, a line of genetically engineered Yorkshire pigs 
capable of digesting plant phosphorus more efficiently and thus have low-phosphorus manure, developed at the University of Guelph (Guelph, Canada) (Golovan et al., 2001), lost financial support following years spent in the regulatory system without gaining market approval. The arduous and costly task of potentially gaining approval for products from genetically engineered animals has been a major barrier to their generation, and limits the technology's application in animal agriculture.

The uptake of genetic engineering in the dairy industry could bring about many previously unimaginable enhancements to deliver benefits to the dairy industry and consumers, which are not possible with traditional methods of breeding. A meaningful prospect for use in the future is in regards to animal health. Maintaining healthy cows is a goal of the industry for improved animal welfare, producer economics, and for limiting the use of antibiotics. Furthermore, genetic engineering of livestock has the possibility to increase production to meet the nutritional demands of an ever-increasing human population, to lessen the impact of animal production on the environment, and to have health benefits and disease fighting attributes for humans, among many other imaginable possibilities. The efficiencies of the technologies continue to improve, making their introduction into practice more of a possibility. The impact genomic engineering will have on animal agriculture in the future is now mainly tarrying on the authorization for associated products to enter the food supply along with public support.

\subsection{Genome editing}

Genome editing is a novel technology that enables targeted modification of a gene, therefore allowing humans not only to edit or "correct" unwanted mutations but also to generate new allelic variants in the genome (Jenko et al., 2015). Genomic editing differs from genetic engineering such that it does not involve the use of recombinant DNA and looks to take advantage of existing variation within the species in a new manner. There are parallels between existing traditional selection methods and gene editing, where both aim to increase the frequency of favourable alleles in the species. In some instances, the same changes achieved through gene editing could be realized through traditional selection by selective breeding, generations of backcrossing, or with the appearance of chance mutations. The benefits of gene editing arise in the ability to make these changes rapidly and without the transmission of linked genes, and relying on random chance transmission of combinations of favourable alleles.

Gene editing methods capable of targeting specific locations of the genome were based on the use of homologous recombination where nucleic acid templates including sequences homologous to either side of a targeted and introduced double-stranded break. Developments in gene editing tools which initiate site-specific DNA double-strand breaks by chimeric designer nucleases like site-directed nu- cleases such as zinc-finger nucleases (ZFNs) and transcription activator-like effector nucleases (TALENs) delivered refined and efficient methods to produce edits in large, complex animal genomes. More recently, a significant advancement in gene editing technology came with the introduction of the RNA-guided nucleases of the clustered regulatory interspersed short palindromic repeat (CRISPR/Cas) associated system. The CRISPR/Cas associated system has emerged as a simpler and more attractive alternative to ZFNs and TALENs, which are complex and expensive. A prospective tool to complement gene editing and better transmit edited genes (or an existing variant) through the population may be genetically engineered gene drivers (Burt, 2003). Different gene drive systems are still under investigation for application in natural populations but could improve the efficiency of the spread of edited genes by ensuring it is passed to the proceeding generations.

Examples of applications of gene editing have expanded in the literature, and some researchers are hypothesizing developments that may soon emerge in livestock breeding (Van Eenennaam, 2017). Many considered uses of the technology are the same as those already considered in current breeding programs including production, health, and welfare, but with targeted efforts on known causative variants. Examples of edited dairy cattle include cattle with increased resistance to tuberculosis (Wu et al., 2015), the knockout of the betalactoglobulin gene (Yu et al., 2011), and enhanced mastitis resistance (Liu et al., 2013, 2014). A promising first use of gene editing in the dairy industry to address welfare issues may be the production of hornless dairy cattle with the introduction of the POLLED allele, which is nearly fixed in some beef breeds but low in frequency in Holsteins (Carlson et al., 2016). Other animal agriculture species are also making headway in the production of edited species, including pigs resistant to porcine reproductive and respiratory syndrome virus that are now being produced (Whitworth et al., 2016). Advances in the understanding of the influence of various genes and genomic variants on phenotypes will bring forth many future opportunities for the improvement of quantitative traits through gene editing.

The regulations and legislature that kept the majority of genetically engineered livestock out of the marketplace may not apply to genome-edited livestock (Waltz, 2012). This is in part due to the difficulty of recognizing edited animals. The effects of genome editing are unidentifiable in the receiving animal, as the method is highly precise and does not change the genome in a way different than would be achievable through selective breeding or natural mutation. By adding or removing genetic variants found in other animals of the same species (and not foreign DNA), advocates of the technologies hope the concerns of many regulators and members of the public may be diminished (Laible et al., 2015; Ruan et al., 2017). The regulatory oversight and implementation has yet to be determined. 
Genome editing tools could find a use alongside existing selection tools in the dairy industry in a complementary role. The most recognizable option for their use is for traits controlled by single genes or by loci exhibiting large effects on a phenotype. Advances and widespread use of genotyping technologies have afforded the possibility to identify alleles with large effects on traits of interest, and the results of GWAS can be put into practical use or validated using gene editing. Gene editing permits the increase in frequency of favourable alleles in a more rapid manner than traditional breeding and without the added intricacy of linkage. The majority of phenotypic traits in dairy cattle under selection are considered to be complex and largely determined by many different genes, each with small effects. In such traits, it may be difficult to determine which sites to target for editing. A possible situation could be the use of editing for largeeffect loci, while continuing to employ traditional selection practices to select for the many loci with small effects (Van Eenennaam, 2017). Genome editing technology is at the forefront of novel tools in animal breeding. The advancements in the technology are accelerating; improving the efficiency, eliminating off-target edits, and introducing multiplex editing events could make the technology more practicable for use in livestock selection programs.

\section{Considerations for the adoption of technologies}

As discussed previously, novel technologies have been, and are being, developed with the potential to revolutionize genetic improvement of the dairy cattle population. However, even if the technologies certainly led to improved animals or dissemination of elite genetics, other additional factors need to be considered. Some technologies such as AI have experienced rapid acceptance and adoption by the industry and had an extensive impact. Not all technologies have experienced the same welcoming. Several factors should be contemplated and could impede the acceptance of technologies. Here we outline considerations related to genetic diversity, economics, and the acceptance of society.

\subsection{Genetic diversity}

An important topic in dairy cattle breeding today is the state of genetic diversity in the population and the implications of its decline. Intensive selection within the dairy cattle population has resulted in remarkable genetic gains in several traits such as milk production. This success was a result of numerous achievements in breeding methodologies as well as computing, reproductive, and genotyping technologies. However, a notable consequence of the genetic gains has been increasing trends in inbreeding levels. Inbreeding has been implicated in reduced performance for certain traits, particularly fitness traits. This noted inbreeding depression has been linked with reduced production and reproductive performance in dairy cows (González-Recio et al., 2007;
Pryce et al., 2014). As new technologies emerge and afford new opportunities for genetic improvement of dairy cattle, it is imperative to consider the impact these tools could have on genetic diversity. Historically, the introduction of novel tools for animal breeders has altered genetic diversity by changing not only the structure of the breeding population but also which candidates are being selected.

Reproductive technologies have enabled the widespread dispersal of elite genetics across the globe and increased rates. Artificial insemination technologies greatly increased the number of progeny produced by top dairy sires and lowered the effective male population size. Superior AI sires were able to leave thousands of daughters along with sons also sampled by AI units, and, therefore, few individuals made large contributions to the next generations. An alternative viewpoint is that $\mathrm{AI}$ granted producers to use multiple sires in their herds, which would lessen the overall impact of AI on the overall population's inbreeding (Young, 1984). The use of embryo transfer offered the same effect for the female population, but on a much less dramatic scale, giving elite dams the opportunity to produce more offspring and have a greater influence on the next generation than would naturally be possible. A loss of genetic diversity could also be a concern if the practice of cloning were to take a stronghold on the industry. Cloning by definition is the production of a genetically identical copy of an individual. This would generate a much greater influence of these genetics within the population through this process and in the future breeding of these animals. The overall strategy for incorporating these technologies into breeding programs can determine the overall impact on inbreeding levels.

Reproductive technologies may also prove to be a conservator of genetic diversity for the dairy industry. Cryopreserved semen and embryos harbour historical genetic variability that could be reintroduced in the future with the aid of other reproductive technologies. Artificial insemination, embryo transfer, and cloning can serve to propagate genetic diversity with breeding strategies geared toward maximizing diversity as opposed to trait improvement.

The accumulation of inbreeding as a result of genomic selection in the dairy industry compared to traditional selection practices has been debated. The estimation of the Mendelian sampling term and differentiation between siblings in traditional BLUP breeding schemes is difficult, because siblings tend to be co-selected and some animals may not have enough data. Contrastingly, genomic selection may decrease inbreeding rates per generation as it is able to discriminate young genotyped siblings, enabling more across family selection by providing knowledge of the Mendelian sampling term (Daetwyler et al., 2007). However, one of the major benefits of genomic selection, the ability to substantially decrease the generation interval, may result in an increased yearly rate of inbreeding.

A secondary utility of genotyping technologies to the dairy industry has been to monitor and characterize inbreeding on 
a genomic level. Traditional pedigree estimates of inbreeding are typically underestimated due to pedigree errors and are considered averages, as the transmission of various segments of the genome from parents cannot be known. Genomics can quantify inbreeding and relationships by capturing the deviations that occur due to Mendelian sampling and define a more precise relationship between individuals (Hill and Weir, 2011). Genomic inbreeding may be estimated from the genomic relationship matrix (VanRaden, 2008) or as runs of homozygosity (ROH) (McQuillan et al., 2008). Runs of homozygosity are segments of consecutive homozygous genotypes that result in an individual due to the transmission of identical haplotypes from parents to their offspring. The characterization of $\mathrm{ROH}$ across the genome gives a new way to examine levels of genetic diversity and causes of inbreeding depression at region-specific levels as well as genomewide (Howard et al., 2017). Genome-wide inbreeding metrics are not able to account for the fact that homozygosity or loss of genetic diversity may have very different effects. The presence of $\mathrm{ROH}$ at certain locations has been found to have detrimental effects in dairy cattle, while some may be inconsequential (Pryce et al., 2014; Kim et al., 2015). The frequency of ROH in dairy cattle is not uniform across the genome and may correlate with regions putatively under selection (Purfield et al., 2012; Zhang et al., 2015). Genetic selection may put substantial pressure on specific locations of the genome and generate increased homozygosity in those regions with large effects on traits under selection. Genomic inbreeding metrics may be more valuable indicators of inbreeding, and an informative tool for use in future breeding strategies and the management of genetic diversity.

Similar to any tool used in selection, the accumulation of inbreeding and loss of genetic diversity is a consideration for the inclusion of gene editing technologies into breeding strategies. The use of genome editing for the introduction, increase in frequency, and fixation of favourable alleles into the population could decrease the genomic diversity in the population. In their simulation study, Jenko et al. (2015), when investigating limitations to editing resources, noted greater increases in inbreeding when more edits were performed on a small number of sires compared to fewer edits on each of a larger number of sires. With the presence of the larger number of sires with edits, inbreeding increases were similar to a scenario only using genomic selection. The inefficiencies in gene editing methods, along with poor reproductive performances and long gestation periods of cattle, may limit the available number of foundation animals in a geneedited population. Ideally, a large number of edited foundation sires would need to be used to propagate the beneficial alleles to the population and maintain background genetic variation and avoid excessive inbreeding (Ruan et al., 2017). As occurs with sires identified as being genetically superior by other more traditional breeding methods, high merit genetics are in demand and more widely used throughout the cow population. Genome editing could also help introduce new genetic variation or correct genetic defects in current genetic resources that otherwise hamper their use.

Genetic diversity in the dairy population is an important consideration for any breeding strategy applied. Novel tools being studied for use in dairy cattle breeding have potential to decrease genetic diversity, but they may also present new ways to monitor and introduce new sources of variation, depending on the goal of their use. It will be important with any technology used in a breeding scheme to maintain awareness of the state of genetic diversity in order to not surrender variation needed for future sustainability. With proper foresight, emerging technologies in animal breeding can achieve genetic progress while still maintaining acceptable rates of inbreeding.

\subsection{Economics}

The commercialization of novel technologies in animal breeding is contingent on economic value. Generally, advancements in technology and increased adoption have brought costs of tools like genotyping to reasonable costs, making their use feasible for producers. In animal breeding, technologies and methods that improve genetic gain have the ability to provide economic returns that recur year after year due to the accumulating genetic improvement. As the costs of implementing new genomic tools decrease, the benefits they create in terms of genetic improvement of many economically important traits are appealing. The economic benefits of genotyping dairy cattle and genomic selection are great in terms of increased genetic and therefore monetary gain, as well as generating remarkable savings in the progeny testing of bulls (Schaeffer, 2006). The hefty costs of whole-genome sequencing at their current price point can presently not be offset by added genetic gains, and therefore sequencing has only found a place in research. This may change with altering protocols and valuable results culminating from this work. Novel applications of NGS technology such as GBS have also emerged to provide an economical means of producing genotypes for a large number of variants.

For some technologies, the prohibitive factor may not be the actual cost, but other factors including efficiency and returns. With sexed semen, McCullock et al. (2013) found profitability was not largely affected by added costs of sexed semen, but more so by management variables like conception rate and the market environment. Genomic engineering and gene editing are both currently afflicted with high costs and relatively poor efficiencies in producing modified, viable young. The gains achieved with these methods can be very diverse and are dependent on the exact application. As prices lessen and efficiencies continue to improve, they may emerge as profitable tools or beneficial in other regards such as welfare. An economic analysis of new genomic technologies requires a detailed review modelling their impact on costs and benefits across all aspects of the industry. 


\subsection{Societal acceptance}

An important discussion with the development of new breeding tools and technologies is the ethical implications of their use and how they will be received by society. Developed technologies may have applications that could provide benefits to the dairy industry and considered as integral and revolutionary by scientists, but may bring elements of concern from the public. These concerns must be acknowledged and addressed or such pioneering developments may never come into practice.

Many reproductive technologies, such as AI and embryo transfer, have become commonplace in the dairy industry. Many members of the public may not be aware of the entailments of these procedures and the "unnaturalness" of reproduction for these animals. The consumer generation that is arriving is more informed and more involved than many in the past. Society is aware of animal welfare, and the use of biotechnology in food production has been in the forefront of mainstream media. One of the major barriers facing the use of technologies like cloning, genetic engineering, and genome editing is the public's perception and concern. Research into public concerns has focused on perceptions of risk, benefit, ethical- or value-related concerns such as "unnaturalness", trust of information and their sources, and acceptance with various applications (Frewer et al., 2013). The opinion of the public on the use of genetically engineered animals may shift depending on their application. The acceptance for pharmaceutical production has been more welcomed than for food production (Laible et al., 2015). Applications that favour human health, animal health, or other publicly recognized benefits could be more presentable to consumers than increasing production. In addition, geography has an effect on acceptance as European consumers tended to be more against genetic engineering applications than North American and Asian nations (Frewer et al., 2013). Consumers hopefully will more readily accept gene-editing technologies than genomic engineering in livestock because it does not involve foreign DNA, it changes the DNA in a very precise manner, and it is similar to natural mutation (Ruan et al., 2017). However, many of the negative connotations of genetic modification may carry over and impact opinion of this technology too in an ill-informed audience (Bruce, 2017). Scientists, industry, and regulatory agencies need to help educate the public and producers on the risks and benefits and the products and enact standards and regulations (Ruan et al., 2017). Public support of emerging technologies will ultimately decide how commonplace such practices in the industry are, as even with regulatory approval, the product must be wanted. With an expanding population to feed, demands will be placed on the agriculture industry. As indicated by Simianer (2016), someday the population may not be able to afford the luxury of not using such novel technologies and resources, as the risk of not using may be great.

\section{Conclusions}

Both high-throughput genomic technologies and advanced reproductive technologies have had, and will continue to have, disruptive effects on livestock breeding practices. Advances in reproductive technologies, "omics", and genetic modification are being made at an unprecedented rate, and large-scale implementation of these technologies will affect both genetic diversity of future livestock populations as well as the economics of genetic improvement. Furthermore, with an active, information-seeking consumer cohort entering the marketplace, past breeding goals centred on production may no longer be attractive and new phenotypes will need to be collected on a large scale. The implications of increasing the use of reproductive and genomic technologies, as well as applying novel technologies and methodologies in livestock breeding populations, must be carefully considered. In particular, the effects on genetic diversity of livestock populations, the financial implications for all stakeholders, and the societal acceptance of these technologies and their widespread use must be evaluated. Despite these caveats, the use of these technologies, together with the ability to collect much more detailed phenotypes, could open the door to sustainable and rapid genomic improvement if properly managed.

Competing interests. The authors declare that they have no conflict of interest.

Acknowledgements. The authors would like to acknowledge Nina Melzer, two anonymous reviewers, and Filippo Miglior for contributing to the quality of this manuscript. This work was written with support from the Alberta Innovates Technology Futures, Alberta Milk, the Dairy Cattle Genetics Research and Development (DairyGen) Council, the National Science and Engineering Research Council of Canada and the Ontario Centres of Excellence.

Edited by: Nina Melzer

Reviewed by: two anonymous referees

\section{References}

Abdalla, E., Peñagaricano, F., Byrem, T., Weigel, K., and Rosa, G.: Genome-wide association mapping and pathway analysis of leukosis incidence in a US Holstein cattle population, Anim. Genet., 47, 395-407, 2016.

Aliloo, H., Pryce, J. E., González-Recio, O., Cocks, B. G., and Hayes, B. J.: Accounting for dominance to improve genomic evaluations of dairy cows for fertility and milk production traits, Genet. Sel. Evol., 48, 8-19, 2016.

Baes, C. F., Dolezal, M. A., Koltes, J. E., Bapst, B., FritzWaters, E., Jansen, S., Flury, C., Signer-Hasler, H., Stricker, C., Fernando, R., Fries, R., Moll, J., Garrick, D. J., Reecy, J. M., and Gredler, B.: Evaluation of variant identification methods for 
whole genome sequencing data in dairy cattle, BMC Genomics, 15, 948, https://doi.org/10.1186/1471-2164-15-948, 2014.

Baruselli, P., Ferreira, R., Sales, J., Gimenes, L., Sá Filho, M., Martins, C., Rodrigues, C., and Bó, G.: Timed embryo transfer programs for management of donor and recipient cattle, Theriogenology, 76, 1583-1593, 2011.

Berendt, F. J., Fröhlich, T., Bolbrinker, P., Boelhauve, M., Güngör, T., Habermann, F. A., Wolf, E., and Arnold, G. J.: Highly sensitive saturation labeling reveals changes in abundance of cell cycle-associated proteins and redox enzyme variants during oocyte maturation in vitro, Proteomics, 9, 550-564, 2009.

Beuzen, N. D., Stear, M. J., and Chang, K. C.: Molecular markers and their use in animal breeding, Vet. J., 160, 42-52, 2000.

Blake, G. E. and Watson, E. D.: Unravelling the complex mechanisms of transgenerational epigenetic inheritance, Curr. Opin. Chem. Biol., 33, 101-107, 2016.

Bó, G. A., Peres, L. C., Cutaia, L. E., Pincinato, D., Baruselli, P. S., and Mapletoft, R.: Treatments for the synchronisation of bovine recipients for fixed-time embryo transfer and improvement of pregnancy rates, Reprod. Fert. Develop., 24, 272-277, 2011.

Boichard, D., Chung, H., Dassonneville, R., David, X., Eggen, A., Fritz, S., Gietzen, K. J., Hayes, B. J., Lawley, C. T., Sonstegard, T. S., Van Tassell, C. P., VanRaden, P. M., Viaud, K., and Wiggans, G. R.: Design of a bovine low-density SNP array optimized for imputation, Plos One, 7, e34130, https://doi.org/10.1371/journal.pone.0034130, 2012.

Boichard, D., Ducrocq, V., Croiseau, P., and Fritz, S.: Genomic selection in domestic animals: principles, applications and perspectives, C. R. Biol., 339, 274-277, 2016.

Boro, P., Naha, B. C., Madkar, A., and Prakash, C.: Sexing of semen in bulls: a mini review, IJAR, 2, 460-462, 2016.

Brinster, R. L., Chen, H. Y., Trumbauer, M., Senear, A. W., Warren, R., and Palmiter, R. D.: Somatic expression of herpes thymidine kinase in mice following injection of a fusion gene into eggs, Cell, 271, 223-231, 1981 .

Brophy, B., Smolenski, G., Wheeler, T., Wells, D., L'Huillier, P., and Laible, G.: Cloned transgenic cattle produce milk with higher levels of beta-casein and kappa-casein, Nat. Biotechnol., 21, 157-162, 2003.

Bruce, A.: Genome edited animals: learning from GM crops?, Transgenic. Res., 26, 385-398, 2017.

Burt, A.: Site-specific selfish genes as tools for the control and genetic engineering of natural populations, P. Roy. Soc. Lond. B. Bio., 270, 921-928, 2003.

Carlson, D. F. and Lancto, C. A.: Production of hornless dairy cattle from genome-edited cell lines, Nat. Biotechnol., 34, 479-482, 2016.

Chan, A. W., Homan, E. J., Ballou, L. U., Burns, J. C., and Bremel, R. D.: Transgenic cattle produced by reverse-transcribed gene transfer in oocytes, P. Natl. Acad. Sci. USA, 95, 1402814033, 1998.

Chasman, D. I.: On the utility of gene set methods in genomewide association studies of quantitative traits, Genet. Epidemiol., 32, 658-668, 2008.

Cook, J. T., McNiven, M. A., Richardson, G. F., and Sutterlin, A. M.: Growth rate, body composition and feed digestibility/conversion of growth-enhanced transgenic Atlantic salmon (Salmo salar), Aquaculture, 188, 15-32, 2000.
Coughlin, S. S.: Toward a road map for global -omics: a primer on -omic technologies, Am. J. Epidemiol., 180, 1188-1195, 2014.

Couldrey, C. and Cave, V.: Assessing DNA methylation levels in animals: choosing the right tool for the job, Anim. Genet., 45, 15-24, 2014.

Daetwyler, H. D., Villanueva, B., Bijma, P., and Woolliams, J. A.: Inbreeding in genome-wide selection, J. Anim. Breed. Genet., 124, 369-376, 2007.

Daetwyler, H. D., Capitan, A., Pausch, H., Stothard, P., Van Binsbergen, R., Brandum, R. F., Liao, X., Djari, A., Rodriguez, S., Grohs, C., Jung, S., Esquerre, D., Gollnick, N., Rossignol, M., Klopp, C., Rocha, D., Fritz, S., Eggen, A., Bowman, P., Coote, D., Chamberlin, A., Van Tassell, C. P., Huggsle, I., Goddard, M., Guldbrandsten, B., Lund, M. S., Veerkamp, R., Boichard, D., Fries, R., and Hayes, B. J.: Whole-genome sequencing of 234 bulls facilitates mapping of monogenic and complex traits in cattle, Nat. Genet., 46, 858-865, 2014.

De Donato, M., Peters, S. O., Mitchell, S. E., Hussain, T., and Imumorin, I. G.: Genotyping-By-Sequencing (GBS): a novel, efficient and cost-effective genotyping method for cattle using next-generation sequencing, Plos One, 8, e62137, https://doi.org/10.1371/journal.pone.0062137, 2013.

Dekkers, J. C. M: Commercial application of marker- and geneassisted selection in livestock: strategies and lessons, J. Anim. Sci., 82, E313-328, 2004.

Doherty, R., Whiston, R., Cormican, P., Finlay, E. K., Couldrey, C., Brady, C., O'Farrelly, C., and Meade, K. G.: The CD4+ T cell methylome contributes to a distinct CD4+ T cell transcriptional signature in Mycobacterium bovis-infected cattle, Sci. Rep.-UK, 6, 31014, https://doi.org/10.1038/srep31014, 2016.

Elshire, R. J., Glaubitz, J. C., Sun, Q., Poland, J. A., Kawamoto, K., Buckler, E. S., and Mitchell, S. E.: A robust, simple GenotypingBy-Sequencing (GBS) approach for high diversity species, Plos One, 6, e19379, https://doi.org/10.1371/journal.pone.0019379, 2011.

Elsik, C. G., Tellam, R. L., Worley, K. C., et al.: The genome sequence of taurine cattle: a window to ruminant biology and evolution, Science, 324, 522-528, https://doi.org/10.1126/science.1169588, 2009.

Flint, A. and Woolliams, J.: Precision animal breeding, Philos. T. Roy. Soc. B, 363, 573-590, 2008.

Foote, R. H.: The history of artificial insemination: selected notes and notables, J. Anim. Sci., 80, 1-10, 2002.

Frewer, L. J., van der Lans, I. A., Fischer, A. R., Reinders, M. J., Menozzi, D., Zhang, X., van den Berg, I., and Zimmermann, K. L.: Public perceptions of agri-food applications of genetic modification - a systematic review and meta-analysis, Trends Food Sci. Tech., 30, 142-152, 2013.

Funk, D.: Major advances in globalization and consolidation of the artificial insemination industry, J. Dairy Sci., 89, 1362-1368, 2006.

Garrick, D. and Ruvinsky, A.: The genetics of cattle, CABI Publishing, New York, 2014.

Golovan, S. P., Meidinger, R. G., Ajakaiye, A., Cottrill, M., Wiederkehr, M. Z., Barney, D. J., Plante, C., Pollard, J. W., Fan, M. Z., Hayes, M. A., Laursen, J., Hjorth, J. P., Hacker, R. R., Phillips, J. P., and Forsberg, C. W.: Pigs expressing salivary phytase produce low-phosphorus manure, Nature, 19, 741-745, 2001. 
González-Recio, O., López De Maturana, E., and Gutiérrez, J. P.: Inbreeding depression on female fertility and calving ease in Spanish dairy cattle, J. Dairy Sci., 90, 5744-5752, 2007.

Gorjanc, G., Cleveland, M. A., Houston, R. D., and Hickey, J. M.: Potential of genotyping-by-sequencing for genomic selection in livestock populations, Genet. Sel. Evol., 47, 12-25, 2015.

Green, B. B. and Kerr, D. E.: Epigenetic contribution to individual variation in response to lipopolysaccharide in bovine dermal fibroblasts, Vet. Immunol. Immunop., 157, 49-58, 2014.

Green, B. B., McKay, S. D., and Kerr, D. E.: Age dependent changes in the LPS induced transcriptome of bovine dermal fibroblasts occurs without major changes in the methylome, BMC Genomics, 16, 30-45, 2015.

Grossniklaus, U., Kelly, W. G., Ferguson-Smith, A. C., Pembrey, M., and Lindquist, S.: Transgenerational epigenetic inheritance: how important is it?, Nat. Rev. Genet., 14, 228-235, 2013.

Hammer, R. E., Pursel, V. G., Rexroad, C. E., Wall, R. J., Bolt, D. J., Ebert, K. M., and Brinster, R. L.: Production of transgenic rabbits, sheep and pigs by microinjection, Nature, 315, 680-683, 1985.

Hansen, P. J.: Current and future assisted reproductive technologies for mammalian farm animals, in: Current and Future Reproductive Technologies and World Food Production, edited by: Lamb, G. C. and DiLorenzo, N., Springer, New York, 1-22, 2014.

Hayes, B. J., Bowman, P. J., Chamberlain, A. J., and Goddard, M. E.: Invited review: genomic selection in dairy cattle: progress and challenges, J. Dairy Sci., 92, 433-443, 2009.

Hazel, L. N.: The genetic basis for constructing selection indexes, Genetics, 28, 476-490, 1943.

Heard, E. and Martienssen, R. A.: Transgenerational epigenetic inheritance: myths and mechanisms, Cell, 157, 95-109, 2014.

Henderson, C. R.: Estimation of variance and covariance components, Biometrics, 9, 226-252, 1953.

Henderson, C. R.: Best linear unbiased estimation and prediction under a selection model, Biometrics, 31, 423-447, 1975.

Hill, W. G. and Weir, B. S.: Variation in actual relationship as a consequence of Mendelian sampling and linkage, Genet. Res. Camb., 93, 47-64, 2011.

Horner, D. S., Pavesi, G., Castrignano, T., D’Onorio De Meo, P., Liuni, S., Sammeth, M., Picardi, E., and Pesole, G.: Bioinformatics approaches for genomics and post genomics applications of next-generation sequencing, Brief. Bioinform., 11, 181-197, 2010.

Howard, J. T., Pryce, J. E., Baes, C., and Maltecca, C.: Invited review: inbreeding in the genomics era: inbreeding, inbreeding depression, and management of genomic variability, J. Dairy Sci., 100, 6009-6024, 2017.

Inbar-Feigenberg, M., Choufani, S., Butcher, D. T., Roifman, M., and Weksberg, R.: Basic concepts of epigenetics, Fertil. Steril., 99, 607-615, 2013.

Jabed, A., Wagner, S., McCracken, J., Wells, D. N., and Laible, G.: Targeted microRNA expression in dairy cattle directs production of beta-lactoglobulin-free, high-casein milk, P. Natl. Acad. Sci. USA, 109, 16811-16816, 2012.

Jaton, C., Schenkel, F. S., Malchiodi, F., Sargolzaei, M., Price, C. A., Baes, C. F., and Miglior, F.: Genetic analysis for quality of frozen embryos produced by Holstein cattle donors in Canada, J. Dairy Sci., 100, 7320-7329, 2017.
Jenko, J., Gorjanc, G., Cleveland, M. A., Varshney, R. K., Whitelaw, C. B. A., Woolliams, J. A., and Hickey, J. M.: Potential of promotion of alleles by genome editing to improve quantitative traits in livestock breeding programs, Genet. Sel. Evol., 47, 55-69, 2015.

Keefer, C. L.: Artificial cloning of domestic animals, P. Natl. Acad. Sci. USA, 112, 8874-8878, 2015.

Khatib, H.: Single nucleotide polymorphisms associated with bull fertility, US Patent No. 9102985, http://www.freepatentsonline. com/20140045711.pdf (last access: 19 October 2017), 2014.

Kim, E.-S., Sonstegard, T. S., Van Tassell, C. P., Wiggans, G., and Rothschild, M. F.: The relationship between runs of homozygosity and inbreeding in Jersey cattle under selection, Plos One, 10, e0129967, https://doi.org/10.1371/journal.pone.0129967, 2015.

Kohda, T. and Ishino, F.: Embryo manipulation via assisted reproductive technology and epigenetic asymmetry in mammalian early development, P. Roy. Soc. Lond. B. Bio., 368, https://doi.org/10.1098/rstb.2012.0353, 2013.

Kremenskoy, M., Kremenska, Y., Suzuki, M., Imai, K., Takahashi, S., Hashizume, K., Yagi, S., and Shiota, K.: Epigenetic characterization of the $\mathrm{CpG}$ islands of bovine Leptin and POU5F1 genes in cloned bovine fetuses, J. Reprod. Develop., 52, 277-285, 2006.

Kropp, J., Carrillo, J. A., Namous, H., Daniels, A., Salih, S. M., Song, J., and Khatib, H.: Male fertility status is associated with DNA methylation signatures in sperm and transcriptomic profiles of bovine preimplantation embryos, BMC Genomics, 18, 280 295, 2017.

Laible, G., Wei, J., and Wagner, S.: Improving livestock for agriculture - technological progress form random transgenesis to precision genome editing heralds a new era, Biotechnol. J., 10, 109120, 2015.

Lievens, A., Petrillo, M., Querci, M., and Patak, A.: Genetically modified animals: options and issues for traceability and enforcement, Trends Food Sci. Tech., 44, 159-176, 2015.

Liu, X., Wang, Y., Guo, W., Chang, B., Liu, J., Guo, Z., Quan, F., and Zhang, Y.: Zinc-finger nickase-mediated insertion of the lysostaphin gene into the beta-casein locus in cloned cows, Nat. Commun., 4, 2565-2576, 2013.

Liu, X., Wang, Y., Tian, Y., Yu, Y., Gao, M., Hu, G., Su, F., Pan, S., Luo, Y., Guo, Z., Quan, F., and Zhang, Y.: Generation of mastitis resistance in cows by targeting human lysozyme gene to betacasein locus using zinc-finger nucleases, P. Roy. Soc. Lond. B. Bio., 281, https://doi.org/10.1098/rspb.2013.3368, 2014.

Macmillan, K. L.: Recent advances in the synchronization of estrus and ovulation in dairy cows, J. Reprod. Develop., 56, S42-S47, 2010.

Mapletoft, R. J. and Bó, G. A.: The evolution of improved and simplified superovulation protocols in cattle, Reprod. Fert. Develop. 24, 278-283, 2011.

Matukumalli, L. K., Lawley, C. T., Schnabel, R. D., Taylor, J. F., Allan, M. F., Heaton, M. P., O'Connell, J., Moore, S. S., Smith, T. P. L., Sonstegard, T. S., and Van Tassell, C. P.: Development and characterization of a high density SNP genotyping assay for cattle, Plos One, 4, e5350, https://doi.org/10.1371/journal.pone.0005350, 2009.

McCullock, K., Hoag, D. L. K., Parsons, J., Lacy, M., Seidel Jr., G. E., and Wailes, W.: Factors affecting economics of used sexed semen in dairy cattle, J. Dairy Sci., 96, 6366-6377, 2013. 
McQuillan, R., Leutenegger, A. L., Abdel-Rahman, R., Franklin, C. S., Pericic, M., Barac-Lauc, L., SmolejNarancic, N., Janicijevic, B., Polasek, O., Tenesa, A., MacLeod, A. K., Farrington, S. M., Rudan, P., Hayward, C., Vitart, V., Rudan, I., Wild, S. H., Dunlop, M. G., Wright, A. F., Campbell, H., and Wilson, J. F.: Runs of homozygosity in European populations, Am. J. Hum. Genet., 83, 359-372, 2008.

Meuwissen, T. H. E., Hayes, B. J., and Goddard, M. E.: Prediction of total genetic value using genome-wide dense marker maps, Genetics, 157, 1819-1829, 2001.

Mikkola, M. and Taponen, J.: Quality and developmental rate of embryos produced with sex-sorted and conventional semen from superovulated dairy cattle, Theriogenology, 87, 135-140, 2017.

Mikkola, M., Andersson, M., and Taponen, J.: Transfer of cattle embryos produced with sex-sorted semen results in impaired pregnancy rate and increased male calf mortality, Theriogenology, 84, 1118-1122, 2015.

Mills, K. I. and Ramsahoye, B. H.: DNA Methylation Protocols, Springer Science \& Business Media, https://doi.org/10.1385/1592591825, 2002.

Mondou, E., Dufort, I., Gohin, M., Fournier, E., and Sirard, M.-A.: Analysis of microRNAs and their precursors in bovine early embryonic development, Mol. Hum. Reprod., 18, 425-434, 2012.

Moore, K. and Thatcher, W.: Major advances associated with reproduction in dairy cattle, J. Dairy Sci., 89, 1254-1266, 2006.

Mullis, K., Faloona, F., Scharf, S., Saiki, R. K., Horn, G. T., and Erlich, H.: Specific enzymatic amplification of DNA in vitro: the polymerase chain reaction, in: Cold Spring Harbor Symposia on Quantitative Biology, Cold Spring Harbor Laboratory Press, https://doi.org/10.1101/SQB.1986.051.01.032, 51, 263273, 1986.

Murphy, B.: Research in animal reproduction: quo vadimus?, Anim. Reprod., 9, 217-222, 2012.

O'Doherty, A. M., O'Gorman, A., al Naib, A., Brennan, L., Daly, E., Duffy, P., and Fair, T.: Negative energy balance affects imprint stability in oocytes recovered from postpartum dairy cows, Genomics, 104, 177-185, 2014.

Paibomesai, M., Hussey, B., Nino-Soto, M., and Mallard, B. A.: Effects of parturition and dexamethasone on DNA methylation patterns of IFN- $\gamma$ and IL-4 promoters in CD4+ T-lymphocytes of Holstein dairy cows, Can. J. Vet. Res., 77, 54-62, 2013.

Poland, J. A., Brown, P. J., Sorrells, M. E., and Jannink, J.-L.: Development of high-density genetic maps for barley and wheat using a novel two-enzyme genotyping-by-sequencing approach, Plos One, 7, e32253, https://doi.org/10.1371/journal.pone.0032253, 2012.

Pryce, J. E., Haile-Mariam, M., Goddard, M. E., and Hayes, B. J.: Identification of genomic regions associated with inbreeding depression in Holstein and Jersey dairy cattle, Genet. Sel. Evol., 46, 71-85, 2014.

Pryce, J. E., Royal, M. D., Garnsworthy, P. C., and Mao, I. L.: Fertility in the high-producing dairy cow, Livest. Prod. Sci., 86, 125135, 2004.

Purfield, D. C., Berry, D. P., McParland, S., and Bradley, D. G.: Runs of homozygosity and population history in cattle, BMC Genet., 13, 70-81, 2012.

Rabiee, A., Lean, I., and Stevenson, M.: Efficacy of Ovsynch program on reproductive performance in dairy cattle: a metaanalysis, J. Dairy Sci., 88, 2754-2770, 2005.
Rho, G.-J., Johnson, W. H., and Betteridge, K. J.: Cellular composition and viability of demi-and quarter-embryos made from bisected bovine morulae and blastocysts produced in vitro, Theriogenology, 50, 885-895, 1998.

Rodrigues, C., Teixeira, A., Ferreira, R., Ayres, H., Mancilha, R., Souza, A., and Baruselli, P. S.: Effect of fixed-time embryo transfer on reproductive efficiency in high-producing repeat-breeder Holstein cows, Anim. Reprod. Sci., 118, 110-117, 2010.

Rodriguez-Martinez, H.: Assisted reproductive techniques for cattle breeding in developing countries: a critical appraisal of their value and limitations, Reprod. Domest. Anim., 47, 21-26, 2012.

Ruan, J., Xu, J., Chen-Tsai, R. Y., and Li, K.: Genome editing in livestock: are we ready for a revolution in animal breeding industry, Transgenic Res., https://doi.org/10.1007/s11248-017-00497, 2017.

Saadi, H. A. S., Fournier, É., Vigneault, C., Blondin, P., Bailey, J., and Robert, C.: Genome-wide analysis of sperm DNA methylation from monozygotic twin bulls, Reprod. Fert. Develop., 29, 838-843, 2017.

Sahana, G., Guldbrandtsen, B., Bendixen, C., and Lund, M.: Genome-wide association mapping for female fertility traits in Danish and Swedish Holstein cattle, Anim. Genet., 41, 579-588, 2010.

Sales, J., Neves, K., Souza, A., Crepaldi, G., Sala, R., Fosado, M., Campos Filho, E., De Faria, M., Sá Filho, M., and Baruselli, P.: Timing of insemination and fertility in dairy and beef cattle receiving timed artificial insemination using sex-sorted sperm, Theriogenology, 76, 427-435, 2011.

Sampson, J. N., Kidd, K. K., Kidd, J. R., and Zhao, H.: Selecting SNPs to identify ancestry, Ann. Hum. Genet., 75, 539-553, 2011.

Schaeffer, L. R.: Strategy for applying genome-wide selection in dairy cattle, J. Anim. Breed. Genet., 123, 218-223, 2006.

Seidel Jr., G. E.: Sexing mammalian sperm - Where do we go from here?, J. Reprod. Develop., 58, 505-509, 2012.

Shuster, D. E., Kehrli, M. E., Ackermann, M. R., and Gilbert, R. O.: Identification and prevalence of a genetic defect that causes leukocyte adhesion deficiency in Holstein cattle, P. Natl. Acad. Sci. USA, 89, 9225-9229, 1992.

Simianer, H.: Genomic and other revolutions - why some technologies are quickly adopted and others are not, Animal Front., 6, 53-58, https://doi.org/10.2527/af.2016-0008, 2016.

Singh, K., Erdman, R. A., Swanson, K. M., Molenaar, A. J., Maqbool, N. J., Wheeler, T. T., Arias, J. A., Quinn-Walsh, E. C., and Stelwagen, K.: Epigenetic regulation of milk production in dairy cows, J. Mammary Gland Biol., 15, 101-112, 2010.

Sun, L., Gong, Z., Oberst, E. J., Betancourt, A., Adams, A. A., and Horohov, D. W.: The promoter region of interferon-gamma is hypermethylated in neonatal foals and its demethylation is associated with increased gene expression, Dev. Comp. Immunol., 39, 273-278, 2013.

Suravajhala, P., Kogelman, L. J., and Kadarmideen, H. N.: Multiomic data integration and analysis using systems genomics approaches: methods and applications in animal production, health and welfare, Genet. Sel. Evol., 48, 38-52, 2016.

Tagawa, M., Matoba, S., Narita, M., Saito, N., Nagai, T., and Imai, K.: Production of monozygotic twin calves using the blastomere separation technique and Well of the Well culture system, Theriogenology, 69, 574-582, 2008. 
Toyoda, T. and Wada, A.: Omic space: coordinate-based integration and analysis of genomic phenomic interactions, Bioinformatics, 20, 1759-1765, 2004.

van Berkel, P. H., Welling, M. M., Geerts, M., van Veen, H. A., Ravensbergen, B., Salaheddine, M., Pauwels, E. K., Pieper, F., Nuijens, J. H., and Nibbering, P. H.: Large scale production of recombinant human lactoferrin in the milk of transgenic cows, Nat. Biotechnol., 20, 484-487, 2002.

van der Sijde, M. R., Ng, A., and Fu, J.: Systems genetics: from GWAS to disease pathways, BBA-Mol. Basis Dis., 1842, 19031909, 2014.

Van Eenennaam, A. L.: Genetic modification of food animals, Curr. Opin. Biotech., 44, 27-34, 2017.

VanRaden, P. M.: Efficient methods to compute genomic predictions, J. Dairy Sci., 91, 4414-4423, 2008.

Veerkamp, R. and Beerda, B.: Genetics and genomics to improve fertility in high producing dairy cows, Theriogenology, 68 , S266-S273, 2007.

Walker, C. G., Littlejohn, M. D., Meier, S., Roche, J. R., and Mitchell, M. D.: DNA methylation is correlated with gene expression during early pregnancy in Bos taurus, Physiol. Genomics, 45, 276-286, 2013

Wall, R. J., Powell, A. M., Paape, M. J., Kerr, D. E., Bannerman, D. D., Pursel, V. G., Wells, K. D., Talbot, N., and Hawk, H. W.: Genetically enhanced cows resist intramammary Staphylococcus aureus infection, Nat. Biotechnol., 23, 445-451, 2005.

Walsh, S., Williams, E., and Evans, A.: A review of the causes of poor fertility in high milk producing dairy cows, Anim. Reprod. Sci., 123, 127-138, 2011.

Walsh, S. W., Mehta, J. P., McGettigan, P. A., Browne, J. A., Forde, N., Alibrahim, R. M., Mulligan, F. J., Loftus, B., Crowe, M. A., Matthews, D., Diskin, M., Mihm, M., and Evans, A. C. O.: Effect of the metabolic environment at key stages of follicle development in cattle: focus on steroid biosynthesis, Physiol. Genomics, 44, 504-517, 2012.

Waltz, E.: Tiptoeing around transgenics, Nat. Biotechnol., 30, 215217,2012

Wang, K., Li, M., and Bucan, M.: Pathway-based approaches for analysis of genomewide association studies, Am. J. Hum. Genet., 81, 1278-1283, 2007.

Wang, Y., Cao, X., Zhao, Y., Fei, J., Hu, X., and Li, N.: Optimized double-digest genotyping by sequencing (ddGBS) method with high-density SNP markers and high genotyping accuracy for chickens, Plos One, 12, e0179073, https://doi.org/10.1371/journal.pone.0179073, 2017.
Whitworth, K. M., Rowland, R. R., Ewen, C. L., Trible, B. R., Kerrigan, M. A., Cino-Ozuna, A. G., Samuel, M. S., Lightner, J. E., McLaren, D. G., Mileham, A. J., Wells, K. D., and Prather, R. S.: Gene-edited pigs are protected from porcine reproductive and respiratory syndrome virus, Nat. Biotechnol., 34, 20-22, 2016.

Wilmut, I., Schnieke, A. E., McWhir, J., Kind, A. J., Campbell, K. H. S.: Viable offspring derived from fetal and adult mammalian cells, Nature, 385, 810-813, 1997.

Wiltbank, M. C., Sartori, R., Herlihy, M. M., Vasconcelos, J. L. M., Nascimento, A. B., Souza, A. H., Ayres, H., Cunha, A. P., Keskin, A., Guenther, J. N., Gumen, A., and Gumen, A.: Managing the dominant follicle in lactating dairy cows, Theriogenology, 76, 1568-1582, 2011.

Wu, H., Wang, Y., Zhang, Y., Yang, M., Lv, J., Liu, J., and Zhang, Y.: TALE nickase-mediated SP110 knockin endows cattle with increased resistance to tuberculosis, P. Natl. Acad. Sci. USA, 112, E1530-E1539, 2015.

Yang, B., Wang, J., Tang, B., Liu, Y., Guo, C., Yang, P., Yu, T., Li, R., Zhao, J., Zhang, L., Dai, Y., and Li, N.: Characterization of bioactive recombinant human lysozyme expressed in milk of cloned transgenic cattle, Plos One, 6, e17593, https://doi.org/10.1371/journal.pone.0017593, 2011.

Young, C. W.: Inbreeding and the gene pool, J. Dairy Sci., 67, 472477, 1984.

Yu, S., Luo, J., Song, Z., Ding, F., Dai, Y., and Li, N.: Highly efficient modification of beta-lactoglobulin (BLG) gene via zincfinger nucleases in cattle, Cell Res., 21, 1638-1640, 2011.

Zhang, Q., Guldbrandtsen, B., Bosse, M., Lund, M. S., and Sahana, G.: Runs of homozygosity and distribution of functional variants in the cattle genome, BMC Genomics, 16, 542-558, 2015.

Zimin, A. V., Delcher, A. L., Florea, L., Kelley, D. R., Schatz, M. C., Puiu, D., Hanrahan, F., Pertea, G., Van Tassell, C. P., Sonstegard, T. S., Marçais, G., Roberts, M., Subramanian, P., Yorke. J. A., and Salzberg, S. L.: A whole-genome assembly of the domestic cow, Bos taurus, Genome Biol., 10, R42, https://doi.org/10.1186/gb-2009-10-4-r42, 2009. 